
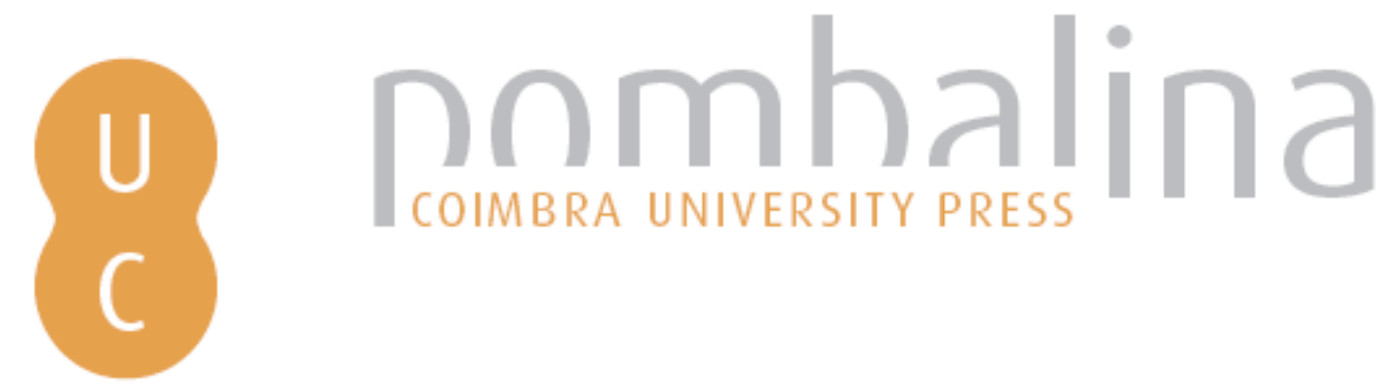

\title{
A crítica hermenêutica à metafísica da subjetividade: a importância de Gadamer e Ricoeur para repensar a linguagem da pólis
}

Autor(es): $\quad$ Portocarrero, Maria Luísa

Publicado por: Imprensa da Universidade de Coimbra

URL

persistente: URI:http://hdl.handle.net/10316.2/39994

DOI: $\quad$ DOl:https://doi.org/10.14195/978-989-26-1115-0_2

Accessed : $\quad$ 26-Apr-2023 02:26:17

A navegação consulta e descarregamento dos títulos inseridos nas Bibliotecas Digitais UC Digitalis, UC Pombalina e UC Impactum, pressupõem a aceitação plena e sem reservas dos Termos e Condições de Uso destas Bibliotecas Digitais, disponíveis em https://digitalis.uc.pt/pt-pt/termos.

Conforme exposto nos referidos Termos e Condições de Uso, o descarregamento de títulos de acesso restrito requer uma licença válida de autorização devendo o utilizador aceder ao(s) documento(s) a partir de um endereço de IP da instituição detentora da supramencionada licença.

Ao utilizador é apenas permitido o descarregamento para uso pessoal, pelo que o emprego do(s) título(s) descarregado(s) para outro fim, designadamente comercial, carece de autorização do respetivo autor ou editor da obra.

Na medida em que todas as obras da UC Digitalis se encontram protegidas pelo Código do Direito de Autor e Direitos Conexos e demais legislação aplicável, toda a cópia, parcial ou total, deste documento, nos casos em que é legalmente admitida, deverá conter ou fazer-se acompanhar por este aviso.

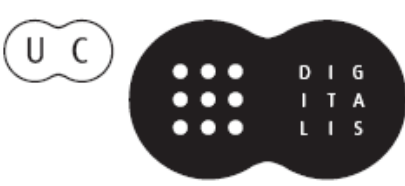




\section{JOÃO CORRÊA-CARDOSO MARIA DO CÉU FIALHO}

(Coordenadores)

\section{A LINGUAGEM NA PÓLIS}

IMPRENSA DA UNIVERSIDADE DE COIMBRA COIMBRA UNIVERSITY PRESS
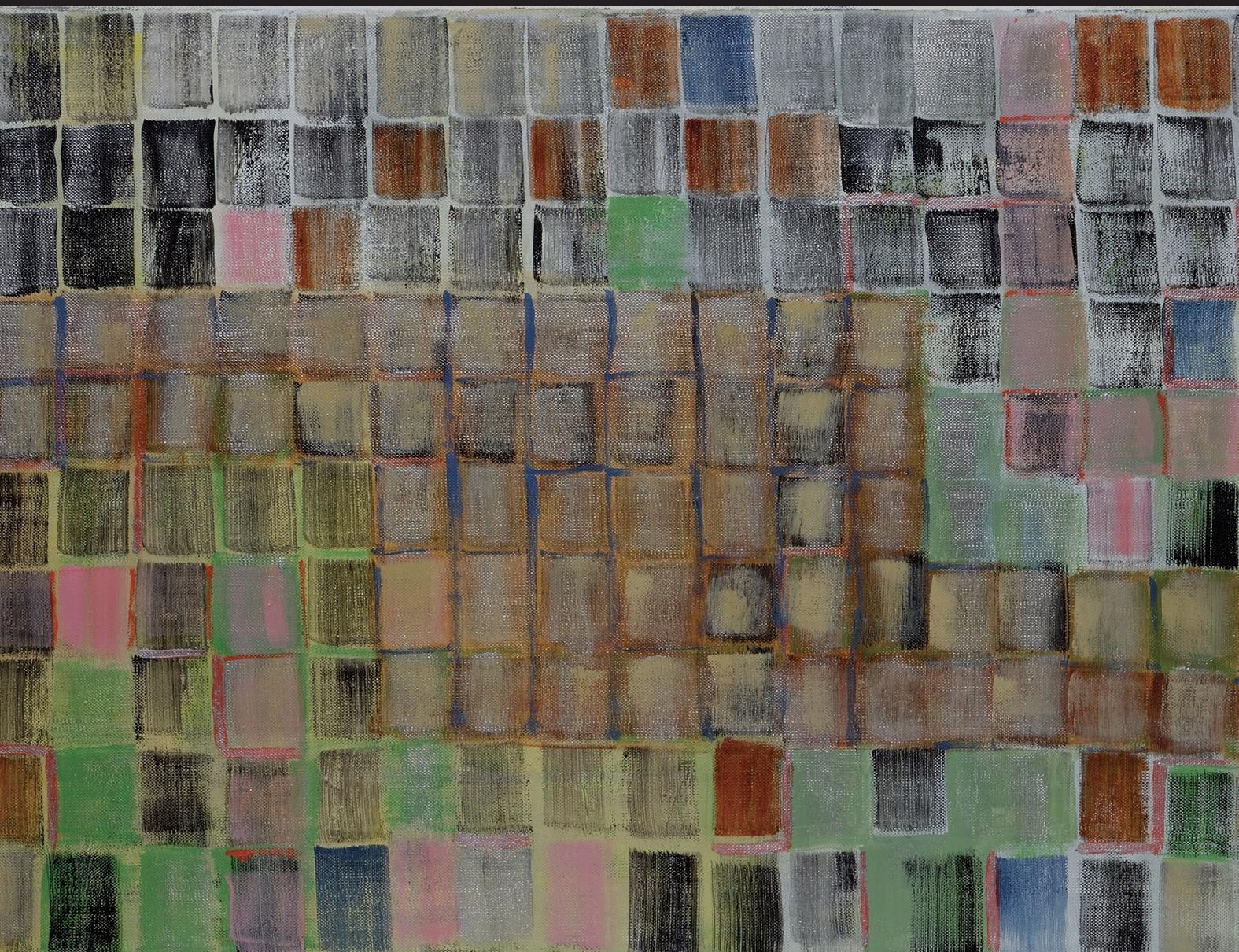
A CRÍTICA HERMENÊUTCA

À METAFÍSICA DA SUBJETIVIDADE:

\title{
A IMPORTÂNCIA DE GADAMER E RICOEUR PARA REPENSAR A LINGUAGEM DA PÓLIS
}

\author{
Maria Luísa Portocarrero \\ Universidade de Coimbra \\ mlp600@gmail.com
}

\begin{abstract}
Resumo: O Cogito cartesiano é sem dúvida uma das formulações mais marcantes do moderno pensamento da subjetividade: pelo seu poder e impacto ele inaugura o reino das filosofias da subjetividade e, com elas, uma determinada linha do pensar que esqueceu o primado da linguagem e da cidade e dominou até ao séc. XX, o horizonte do filosofar. É contra esta metafísica da subjetividade desencarnada, a da modernidade, que acompanha o desenvolvimento da ciência e reduz o mundo a quadro diante do olhar, que a filosofia hermenêutica pós-heideggeriana se insurge. Este artigo procura pensar o contributo da fenomenologia hermenêutica de H.- Gadamer e P. Ricoeur para um novo pensamento da subjetividade e da racionalidade, acentuando a sua dimensão praxística e linguística fundamental.
\end{abstract}

Palavras chave: Subjetividade; racionalidade; linguagem simbólica; praxis; diálogo.

\footnotetext{
Abstract: The Cartesian cogito is undoubtedly one of the most striking formulations of modern subjectivity thought: for its power and impact it opens the realm of subjectivity philosophies and, with them, a certain way of thinking that forgot the primacy of language and the city and he
} 
dominated until the XX century the horizon of philosophy. It is against this metaphysics of disembodied subjectivity, of modernity, which tracks the development of science and reduces the world a table before the eyes that the post-Heideggerian hermeneutics philosophy rebels. This article tries to think the contribution of hermeneutic phenomenology of H.- Gadamer and P. Ricoeur for the new thinking of subjectivity and rationality, accentuating its practical and linguistics fundamental dimension.

Keywords: Subjectivity; rationality; symbolic language; praxis; dialogue.

I - O Cogito cartesiano é, sem dúvida, uma das formulações mais marcantes do moderno pensamento da subjetividade: pelo seu poder e impacto ele inaugurou o reino das filosofias da subjetividade e, com elas, uma determinada linha do pensar que esqueceu o primado da cidade e dominou até ao séc. XX, o horizonte do filosofar. De acordo com este modelo, a própria linguagem era considerada mera roupa de um pensamento uniforme em todos os sujeitos pensantes e a praxis vivida inteiramente conduzida pelo saber científico que, para além de estar em grande desenvolvimento, dissolvia diferenças e procurava já a uniformização.

É justamente contra esta metafísica da subjetividade pura e desencarnada, a da modernidade, que acompanha o desenvolvimento da ciência e reduz o mundo a quadro diante do olhar, que a filosofia hermenêutica pós-heideggeriana se eleva. Ela contesta a referida metafísica em nome do primado da condição finita, logo múltipla, da subjetividade humana, que surge sempre já situada ou mesmo lançada numa família, numa sociedade civil e num Estado, isto é, num mundo sempre recebido. Como tal ela surge situada num espaço já dito, significado e narrado por outros, isto é, num mundo sempre marcado por horizontes relativos e por um fenómeno de transmissão temporal que exige receção da alteridade, diálogo, crítica e apropriação. 
É, pois, sobre a especificidade da conceção hermenêutica de subjetividade enraizada que vamos pensar. Devemos começar por dizer que a Hermenêutica não rejeita a subjetividade como característica do ser humano. Repensa-a no entanto a partir da sua condição corpórea, enraizada e linguística. Mas para nos entendermos realmente, uma vez que vamos falar de conceções diferentes de subjetividade, precisamos de começar por recorrer a Descartes, filósofo que fundou a existência do Cogito, que provou justamente a natureza pensante deste, a sua condição imediata e não relacional, uma vez que o intuito do filósofo era precisamente afastar toda a dúvida e fundar uma racionalidade que conduzisse a certezas:

«Na metafísica de Descartes, o ente foi definido pela primeira vez como a objetividade de uma representação e a verdade como a certeza da representação. Ora, com a objetividade surge a subjetividade, neste sentido segundo o qual o ser certo do objeto é a contrapartida da posição de um sujeito. Assim temos ao mesmo tempo a posição do sujeito e a proposição da representação»" ${ }^{1}$.

Sabemos também que na base de uma tal conceção de subjetividade, a Modernidade pôde desenvolver uma ideia específica de saber, de qualidade claramente operatória e não tanto ética e prática, logo, aquela que, como nos diz Gadamer, "conferiu à ciência experimental um novo estatuto e uma clara importância social e política» ${ }^{2}$. Com ela, instalou-se no Ocidente o valor absoluto da racionalidade calculadora e instrumental que Heidegger tão bem caracteriza na sua conferência Sérénité̉. Esta nova conceção de ciência, puramente

${ }^{1}$ P. Ricoeur, "Heidegger et la question du sujet", in IDEM, Le conflit des interprétations. Essais d’herméneutique, Paris, Seuil, 1969, p. 226.

${ }^{2}$ H-G. Gadamer, Über die Verborgenheit der Gesundheit. Aufsätze und Vorträge. Frankfurt, Subrkamp, 1993, p. 17.

3 M. Heidegger, Gelassenheit, Gunther Neske, Pfullingen, 1959. 
representativa e dominadora, a da racionalidade pragmática e operatória, que veio a dar origem à tecnociência, deixou de lado como não científica toda uma outra forma mais meditativa, simbólica e hermenêutica de pensar e habitar o mundo. Perdeu-se assim definitivamente, lembra-nos Gadamer, o que nos oferecia o conceito grego de racionalidade: um saber integrador, uma forma mais geral do conhecer que refletia, antes de mais, sobre o modo como o homem habita o mundo, isto é, como se eleva acima do seu aqui e agora, formulando "perguntas sobre a verdade e sobre o bem de um modo que não exprima nem o benefício próprio nem o proveito público»4.

A grande tradição da filosofia prática e política da Antiguidade - e o seu horizonte primordialmente ético e deliberativo, retomado com alguma força mais tarde, pela problemática do humanismo e finalmente pelo horizonte das chamadas ciências do espírito no séc. XIX - acabou por desaparecer do horizonte da racionalidade ocidental. Esta, puramente neutra e desinteressada, chegou mesmo a transferir, não sem levantar inúmeros problemas, as suas qualidades de razão operatória e produtiva para o âmbito da praxis moral do humano. O maior de todos eles foi a substituição de toda a cultura, da indagação ou mesmo da educação do ser humano, por toda uma nova cultura baseada na aprendizagem rápida e instrumental de competências e de automatismos que permitissem a adaptação a uma sociedade, cada vez mais burocratizada e administrada. A ideia de método e o primado absoluto deste sobre as coisas foram remetendo paulatinamente para o esquecimento todo o tipo de racionalidade mais deliberativa e dialógica, aquela que não tem tanto a ver com capacidades que se podem exercitar, mas antes de mais com a participação dos cidadãos na vida pública, com a facticidade

\footnotetext{
${ }^{4}$ H.-G. Gadamer, Gesammmelte Werke. Hermeneutik 1. Wabrheit und Methode 1, Tubingen, Mohr, 1986, pp. 12-13.
} 
das crenças, das tradições, dos valores e decisões que permitem fundar a coesão social e, com ela, uma racionalidade responsável.

Por outras palavras, a investigação científica dominante separou-se do ethos $^{5}$, da capacidade de abertura e do enraizamento que caracteriza o humano, enquanto ser dotado de perguntabilidade e distância, isto é, da palavra que se diz ao outro e que por isso mesmo permite sempre compartilhar algo de comum. Desenraizada do mundo da vida, no qual o homem continua a viver e a compreender-se, apesar de tudo, a racionalidade operatória seguiu o seu caminho, impondo o primado da técnica sobre a ação, destruindo crenças e substituindo-as por um valor único: a eficácia. Acabou por converter-se hoje numa séria ameaça que se estende à vida social do homem, isto é, num caminho que inaugura inúmeras transformações do agir humano, reduzindo-o à figura do trabalho ou na linguagem de $\mathrm{H}$. Arendt, à condição do animal laborans.

Assim surge a desorientação ética dos nossos dias e toda uma praxis manipulada ou mesmo disseminada por múltiplas especializações que, sabendo operar com eficácia, não sabem, muitas vezes, o que fazer com os seus próprios resultados. É que, de facto, e como o autor nos recorda: a condução da vida humana segundo o modelo da racionalidade calculadora, primordialmente baseado em automatismos e capacidades técnicas, esquece a interrogação sobre os fins e conduz inevitavelmente a sérios conflitos, que clamam pela necessidade de uma nova racionalidade. ${ }^{6}$ Veja-se, neste sentido, o boom das éticas aplicadas dos dias de hoje e os problemas surgidos desde a segunda metade do séc. XX pela aplicação puramente técnica de teorias fragmentadas e especializadas ao âmbito sempre concreto, afetivo e solidário do mundo vivido dos homens. Todos estes problemas refletem a necessidade de uma outra racionalidade

\footnotetext{
5 Idem, Das Erbe Europas, Frankfurt, Suhrkamp, 1989, p.100

${ }^{6}$ Idem, ibidem, pp. 10-11.
} 
que respeite a autonomia e dignidade do ser humano e o sentido verdadeiramente relacional da sua praxis. Com efeito o homem quando manipulado é um homem alienado e insatisfeito, logo é necessário repensá-lo, a si e à sua razão; o que nos obriga a atualizar a célebre distinção kantiana entre pessoas e coisas, percebendo claramente que o homem visa fins próprios que não se podem, de modo algum, reduzir a um puro cálculo de meios. A lógica instrumental dos meios, aquela que tem transformado radicalmente o agir e que acabou por introduzir hoje a necessidade do questionamento ético, não pode substituir-se a uma ponderação dos fins.

Isto quer dizer que a retomada do Cogito só é hoje possível por meio de um movimento que parta da intencionalidade do mundo vivido e se oriente para a difícil questão do sentido do estar no mundo $^{7}$. Será ele puramente técnico ou visará, como queria Aristóteles, o horizonte da felicidade?

Tal é o motivo da racionalidade hermenêutica: ela sabe que, depois das críticas da filosofia da suspeita à falsa natureza imediata do Cogito e depois da fenomenologia da passividade, há que meditar seriamente o significado da inscrição linguística da subjetividade humana, nomeadamente, a partir do que ficou esquecido pela Modernidade: o mundo da vida com as suas alegrias e tragédias e, por isso, as suas linguagens próprias. A retomada do eu sou passa hoje pela prova da dúvida, logo, exige uma hermenêutica dos testemunhos, dos textos, obras e ações deste único ente que se faz um si mesmo singular e que não se reduz mais à transparência do Cogito. O sum é de facto, uma realidade opaca por detrás do Cogito, excede-o e é este o grande enigma deixado em aberto pelas hermenêuticas da suspeita: o que é que eu sou afinal? Como posso perceber que sou sujeito? Tal é a grande questão a que a hermenêutica apenas responde de forma mediata por meio da compreensão das figuras e testemunhos tempo-

7 P. Ricoeur, Le conflit des interprétations, p. 229 
rais deste sum que deve agora dar testemunho das suas capacidades para finalmente poder ser entendido. Este novo caminho exige um longo desvio hermenêutico pela alteridade e pela relação, quer isto dizer, pela dimensão semântica da nova compreensão de si e pela dos testemunhos, sempre linguageiros da humanidade.

Tal é o eixo da reflexão hermenêutica: a subjetividade atesta-se para si e testemunha-se para os outros; acedemos-lhe então já não pelo modelo da visão, mas pelo da relação, da solicitude e da praxis. Isto é, sempre por meio da atividade e da linguagem deste único ente que é capaz de ser sujeito: "A irrupção da linguagem é a irrupção do ser-aí, pois a irrupção do ser-aí significa que o ser é trazido à palavra na linguagem ${ }^{8}$. Neste sentido, podemos dizer que a hermenêutica filosófica, nomeadamente a de H.- G. Gadamer e de P. Ricoeur, concretizam o programa fenomenológico da urgência de um retorno às próprias coisas, reinterpretando, a partir da linguagem e dos seus usos, a superstição naturalista do primado dos factos.

II - Qual então o significado específico das ideias de subjetividade e racionalidade no horizonte da filosofia hermenêutica contemporânea? Vamos aqui falar de H.- G. Gadamer e de P. Ricoeur, particularmente das suas críticas à moderna limitação da racionalidade filosófica à problemática do conhecimento e à manipulação do mundo, reduzido a paisagem diante do olhar. Refiramo-nos pois, e em primeiro lugar, ao que a hermenêutica rejeita: o modelo de soberania epistemológica e antropológica do sujeito (narcísico) moderno, o famoso Cogito exaltado (nas palavras de Ricoeur) que, já de acordo com o parágrafo 6 de Ser e tempo, partilha dos grandes pressupostos da metafísica. 9 Lembremos que, neste parágrafo, Heidegger nos mostrava que a crítica ao sujeito-Cogito é uma parte integrante

\footnotetext{
8 Idem, ibidem, p. 231.

9 Idem, ibidem, p. 225
} 
da destruição da história da ontologia ${ }^{10}$. Mas entendamo-nos bem quanto a este assunto: a destruição hermenêutica do Cogito não significava aqui uma total aniquilação do $e u$ sou, apenas a ideia de que este tinha de ser reinterpretado, uma vez que, com a questão da finitude e do tempo, a tónica se deslocara de uma filosofia que parte do Cogito, como verdade primeira, para uma filosofia que parte da questão do ser como a questão esquecida no Cogito ${ }^{11}$.

É pois a grande tese que deu origem à modernidade que a Hermenêutica recusa já desde Heidegger. Que tese é esta? A identificação cartesiana de duas noções: a ideia de subjectum como fundamento e a ideia de subjectum enquanto eu. Com Descartes, de facto, o homem tornara-se o primeiro e real subjectum, o primeiro e real fundamento ${ }^{12}$. O que significa que o sujeito, enquanto eu mesmo, se transformara na Modernidade, no centro a partir do qual tudo era entendido; o mundo convertia-se assim num quadro disponível, numa pura representação do Cogito.

Claro que isto só era possível porque se omitia a realidade do sum, por outras palavras, porque a certeza absoluta do Cogito dispensava o filósofo de colocar a questão do sentido deste ente. Foi no contexto da racionalidade científica que surgiu o Cogito, como princípio da subjetividade moderna, o que quer dizer que esta pertence à época do mundo como representação e quadro. "O carácter de representação do ente é o correlato da emergência do homem como sujeito» ${ }^{13}$.

10 Idem, ibidem, p. 224: «La contestation du Cogito constitue une partie de la destruction de 1'histoire de l'ontologie, telle qu'elle est poursuivie dans 1'introduction de Zein und Zeit. Dans le fameux paragraphe consacré à Descartes (§6), nous lisons que l'assertion du Cogito sum procède ' d'une omission essentielle : celle d'une ontologie de 1 'être- là ".

11 Idem, ibidem.

12 Idem, ibidem, p. 226.

13 Idem, ibidem, p. 227. 
Recuperar então o sentido originário do eu sou, isto é, a capacidade que tem o ente humano de se referir a si mesmo como sujeito, exige que a hermenêutica comece por contestar radicalmente o Cogito. Todos conhecemos a primeira frase de Ser e tempo: «a questão do ser caiu hoje no esquecimento». O que é importante nesta afirmação é o facto de o problema do ser passar a surgir como uma questão, a questão do homem, ou mais precisamente acontecer no tratamento do conceito de questão, o qual faz referência a um si mesmo, o interpelado na questão. O ente humano é capaz de ser sujeito porque começa por ser interpelado pela questão do ser. $\mathrm{O}$ Dasein, lembra-nos Heidegger, é um ente especial entre todos os outros, porque é o único tocado pela questão do sentido e orientado pelo questionado, isto é, pela coisa a respeito da qual a questão é colocada $^{14}$. Com esta questão descobre-se, ao mesmo tempo, uma nova possibilidade da filosofia do ego, a filosofia do eu sou um ser interpelado, na medida em que já não sou constituído por certezas mas pela própria indagação. Sou um ser de possibilidades, isto é, não pré-determinado que tem, entre outras, a possibilidade de colocar a questão do ser/sentido. Que ser é este, afinal? Um ser com outros, um ser finito - de outro modo não se questionava - e já lançado numa situação hermenêutica de interação e partilha. É, pois, necessário encarar a finitude e a corporeidade do eu penso e perceber claramente o que a entretece: a dimensão praxística da relação e a experiência de contraste entre o âmbito fáctico que me constitui e o possível da nomeação.

Como perceber então esta dupla dimensão? Há que partir dos signos e indícios, dos textos instituições e do conjunto de testemunhos (história e ficção) que atestam a ligação do eu ao outro, do eu à sua circunstância e, simultaneamente, à dimensão da sua incondicionalidade.

${ }^{14}$ Idem, ibidem, p. 224. 
Por outras palavras, a crítica hermenêutica do Cogito e da racionalidade instrumental aposta na linguagem simbólica da pólis, em sentido lato, dado que acredita na significação relacional do eu sou, isto é, não rejeita totalmente a possibilidade do Cogito. Quer, no entanto, desvinculá-lo de toda a ideia de fundamento e re-interpretá-lo a partir da experiência marcante do séc. XX: a da praxis, a da cidadania e da finitude. Ora, finitude significa estar já lançado numa situação marcada por instituições, sendo a primeira das quais a linguagem; significa partir de tradições e interpretações do mundo, ser um ser relacional, uma praxis de vida, a praxis temporal daquele que se faz questão, palavra, logo que não é já um ser soberano e solitário, mas um núcleo de relações dialogais. É o eu sou relacional, aquilo que a hermenêutica tem em mira: aquele que, nas palavras de Gadamer, quando se descobre, percebe imediatamente a sua inscrição no diálogo, a sua pertença a textos, tradições ou a um efeito de sentido já sempre recebido e aceite como necessário à vida prática. O novo sujeito é o homem da interação, já sempre situado num horizonte plural do sentido, aquele que sempre chega demasiado tarde para suspender todas as suas crenças e diálogos já efetuados e começar tudo de novo, a partir de um grau zero de pressupostos e efeitos históricos.

Com efeito, para a hermenêutica filosófica de Gadamer, e seguidamente para a de Ricoeur, são as condições de possibilidade do agir com outros que permitem perceber o verdadeiro sentido de toda a subjetividade e que determinam ainda o sentido originário da racionalidade. Sem a inscrição num mundo simbólico e axiológico comum não há subjetividade. É o mundo da vida prática governado por valores, crenças e ideários comuns que permite a construção da identidade subjetiva e o enraizamento da racionalidade hermenêutica. Esta sabe que o Cogito moderno representava um sujeito virtual sem corpo nem espaço pois que o humano que é concreto concreto parte sempre de pressupostos, resultado da sua pertença a um horizonte 
cultural e histórico particular e que estes mais não são do que o sintoma de que o real se diz de múltiplos modos, traduzido por diferentes situações, o que quer dizer que devo perceber que só com a alteridade histórica e concreta do outro tu consigo fazer sentido.

A reabilitação do sentido positivo dos pressupostos de todo o conhecer é assim o tema chave da crítica dialógica gadameriana à racionalidade abstrata da modernidade iluminada 15 . Ela lembra-nos, fundamentalmente, que não podemos construir a nossa identidade sem a linguagem do outro. A lente da subjetividade, diz-nos o filósofo,

"é um espelho que deforma. A reflexão sobre si é apenas uma centelha na corrente fechada da vida histórica. Por isso os preconceitos de um indivíduo constituem a realidade histórica do seu ser muito mais do que os seus juizos (...). Se quisermos fazer justiça ao modo finito e histórico do homem, é preciso realizar uma drástica reabilitação do conceito de prejuízo e reconhecer que existem preconceitos legítimos» ${ }^{16}$.

Dada a nossa condição finita começamos, desde logo, por ser herdeiros das ações, significações e avaliações dos outros que nos precederam. No entanto, somos herdeiros ativos e nunca meros repetidores : é a partir da nossa própria questão, de um horizonte novo, concreto e particular, que recebemos o efeito do outro; devemos, por isso, traduzi-lo sempre para a nossa própria linguagem que, por sua vez, se enriquece por meio da maneira como é questionada pela tradição ${ }^{17}$.

\footnotetext{
15 Cf., neste sentido,. M. Luísa Portocarrero Silva, O Preconceito em H-G. Gadamer: Sentido de uma Reabilitação, FCT/ JNICT, 1995.

${ }^{16}$ H.-G. Gadamer, Gesammmelte Werke. Hermeneutik 1. Wahrheit und Methode 1 , p. 281.

17 Cf., neste sentido, H.- G. Gadamer, op. cit., pp. 311-312.
} 
Os preconceitos, sublinhados por Gadamer como condição do exercício da racionalidade plural, cumprem pois uma dupla função : lembram-nos por um lado a condição profundamente fáctica ${ }^{18}$ de toda a racionalidade, logo apontam para algo que nos escapa, a nossa passividade, e sublinham, por outro, a nossa condição profundamente ética e dialógica: somos afinal seres plurais e entes cuja existência resulta dos nossos atos com os outros. Daí a importância dos preconceitos: eles são categorias práticas que nos revelam que a nossa compreensão é um projeto provisório de sentido, uma mediação frágil e provisória, logo capaz de se expor ao outro, à outra cultura ou perspetiva. Esta questiona-me e faz-me finalmente reconhecer que talvez eu não tenha toda a razão ${ }^{19}$. Gadamer defende assim o valor simbólico e formativo do diálogo que nós somos e fala-nos da posição chave da literatura ${ }^{20}$, enquanto medium da relação entre línguas, culturas e diálogo. A própria educação, pela exposição ao texto, é considerada como arte de crescimento interior pelo facto de nos ensinar a poder não ter razão.

São pois as condições humanas da interação, da socialização, da solidariedade e do serviço ao outro ${ }^{21}$, sem nunca esquecer a particularidade própria, que constituem o verdadeiro motivo gadameriano da crítica do primado exclusivo do método e da sua racionalidade estritamente descritiva e operatória. Tal crítica promove um modelo novo de racionalidade, a racionalidade deliberativa, ética e dialógica, cujas grandes categorias são os preconceitos em sentido positivo,

18 Cf. J.GRONDIN, Le tournant herméneutique de la pensée contemporaine, Paris, Puf, 2003, p. 114.

19 H.-G. Gadamer, op. cit., pp. 345-346.

20 Cf. ibidem, p. 165.

21 « Auslegung des gezetzlichen Willens, Auslegung der götlichen Verheissung zu sein, das sind offenkundig nicht Herrschafts-, sondern Dienstformen". Idem, ibidem, p. 316. 
o diálogo dos horizontes historicamente diferentes, a aplicação e a arte de aprender a poder não ter razão.

É esta a problemática central da filosofia hermenêutica de Gadamer: a promoção de uma racionalidade prudencial, próxima da phronesis aristotélica, e tão necessária para responder hoje ao problema da dissolução da coesão social, própria da praxis contemporânea. O filósofo não se cansa de nos lembrar que o que é preciso pensar é a finitude da praxis humana que a ciência moderna esqueceu e confundiu com a praxis técnica dos experts; que a capacidade humana de meditação ou theoria faz parte integrante da praxis $^{22}$; que à natureza humana pertence uma forma simbólica, originária da praxis, que nada tem a ver com o agir conduzido por automatismos de ordem instintiva ou racional. Ela é, pelo contrário, um tipo de ação guiada pela "escolha reflexiva, pela correta antecipação e pela correta ordenação de cada um de nós sob fins comuns» 23 . Reconhecer-se simbolicamente com outros no que é comum e no que não se reduz pelo facto de ser partilhado, comportar-se e atuar em solidariedade ${ }^{24}$, tal é a condição decisiva da praxis que, diferentemente da ação animal, é afã inibido, sabe manter presentes fins remotos a alcançar e deve sempre escolher ou decidir-se em favor de algo e contra algo ${ }^{25}$. A conclusão do silogismo e da reflexão prática, ensinou-nos Aristóteles, é a decisão, daí que no agir prático o homem não atue, apenas de acordo com o próprio arbítrio, mas, pelo contrário, de acordo com os demais, determinando em comum, e através da interação, os assuntos comuns ${ }^{26}$.

22 Cf. H.-G. Gadamer, Vernunft im Zeitalter der Wissenschaft. Aufsaetze, Frankfurt, 1976, pp. 62-65; 82-83; 123-124.

23 Cf. Idem, p.63.

${ }^{24}$ Idem, ibidem. p. 77.

25 Idem, ibidem.,p. 69.

26 Idem, ibidem. p. 70. 
Relembrando Aristóteles e a sua sabedoria prática, pretende Gadamer ultrapassar o verdadeiro embaraço ético dos nossos dias, aquele que se exprime precisamente no esquecimento moderno do valor da deliberação e no problema atual do sentido dos valores:

«a origem deste embaraço filosófico é constituída por um elemento comum à nossa cultura e que diz respeito ao papel desempenhado pela ciência experimental moderna na vida e na consciência da humanidade. A sua intervenção metódica, o seu princípio de construção e verificação, que expõe o mundo dos objetos à produção e regulação através da planificação e do trabalho humano, parece ser inacessível ao ponto de vista normativo. Não é a ciência moderna que deve dirigir e controlar o nosso saber e poder. É esta, em termos gerais, a base comum a todo o filosofar contemporâneo» ${ }^{27}$.

É profundamente ética a tarefa da hermenêutica filosófica, retenhamos, já que ela surge, desde sempre, ligada ao mundo da interação e, por esse mesmo facto, ao que o funda enquanto tal: textos, histórias, valores, leis, que atestam simultaneamente a condição sempre situada e excêntrica do agir humano. Porque é finito e plural, ele nunca pode começar tudo de novo. Parte, pelo contrário, de uma pertença a costumes e tradições que nada são, se não forem capazes de ser traduzidos e aplicados em cada situação concreta da ação singular, ou seja, compreendidos de modo novo e diferente. Daí que Gadamer considere ser a aplicação o núcleo fundamental da racionalidade e da subjetividade hermenêutica. Nela se joga toda a diferença entre saber fazer e saber agir. A racionalidade operatória sabe fazer, sabe intervir no mundo, modificando-o de acordo com um plano previamente determinado ao qual não há que fugir.

27 Idem, op.cit., p. 200. 
Mas ao nível do agir com outros o modelo é diferente: é preciso deliberar, ponderar e decidir em diálogo com o outro horizonte. Já vimos que Gadamer fala em preconceitos e fusão de horizontes diferentes mas vai encontrar o modelo desta nova racionalidade hermenêutica na Ética aristotélica e na hermenêutica jurídica. Recorramos ao modelo da ética aristotélica: o que impressiona Gadamer na Ética de Aristóteles, em suma, o que faz a sua atualidade, é o facto de o Estagirita ter defendido o saber ético, a phronesis, como um conhecimento especial que se adquire pela prática e pela educação, que se realiza no agir e que pressupõe uma relação muito específica entre o universal e o particular. Que relação é esta? Uma verdadeira aplicação hermenêutica:

"O ser ético enquanto comportamento especificamente humano distingue-se do ser natural porque não é pura e simplesmente redutível a um conjunto de capacidades ou forças agentes. O homem é pelo contrário um ser que apenas se torna naquilo que é e adquire o seu comportamento pelo que faz pelo modo como age (...), a tarefa própria da consciência ética é de avaliar uma situação concreta à luz das exigências éticas mais universais» 28 .

Tal é a verdadeira condição do saber agir nas situações quotidianas de vida que pedem uma decisão: saber respeitar a norma e a solicitude para com o outro, isto é, para com a pessoa em jogo na situação que exige avaliação; por outras palavras, o desenvolvimento de uma sabedoria prática, atenta aos conflitos entre a norma e as diferentes situações.

${ }^{28}$ Idem, Le problème de la conscience historique, Paris, Louvain, 1963, pp. 50-51. 
Assim surge uma racionalidade que não esquece a pessoa, a sua constituição marcada pela desproporção e pela falibilidade ${ }^{29}$ tal é, por sua vez, o motivo da crítica ricoeuriana ao Cogito, enquanto princípio da subjetividade e da racionalidade. A filosofia do Cogito esqueceu o homem falível, a sua miséria e o longo caminho de atestação das suas capacidades de mediação ou ação, que começa pela experiência de contraste representada pela confissão enquanto afirmação originária expressa pela linguagem.

Para o filósofo francês o problema começa por ser o da concretização do eu posso da Modernidade, que ele considera profundamente irreal, pensando-o no contexto de um eu quero, por sua vez, marcado pela dialética de voluntário e de involuntário ${ }^{30}$. É a partir de uma filosofia do corpo próprio, em diálogo com as ciências do corpo objeto $^{31}$, que o filósofo francês quer começar a pensar. O objetivo é descobrir, a partir da dialética da passividade e da espontaneidade do homem finito, os signos que nele dão testemunho da emergência do esforço e da liberdade vulnerável, mas apesar de tudo uma capacidade de agir, de iniciar uma nova ordem, por meio de um poder de dizer e escolher.

Para Ricoeur é o mal sofrido pelo homem que obriga a questionar seriamente o tradicional modelo de racionalidade, sempre preocupado com a fundamentação da sua sistematicidade e conhecimento. A racionalidade hermenêutica desistiu da fundamentação absoluta, porque parte da vida que se significa, do que na vida, vivida segundo a forma do tempo e do espaço simbolicamente mediados, escapa às representações puramente teóricas e exige a atestação de uma afirmação originária, que surge com o acontecimento de uma força, a

29 Cf. P. Ricoeur, Philosophie de la volonté. Finitude et culpabilité I L 'bomme faillible.

30 Cf. Idem, ibidem, p. 8.

$31 \mathrm{Cf}$. Idem, Philosophie de la volonté. Le volontaire et l'involontaire, Paris, Aubier, 1967. 
de um eu sou que, dominado muitas vezes pelo sofrimento, acontece desde logo na relação com o outro, estabelecida pela linguagem não concetual da confissão ou lamentação ${ }^{32}$. Trata-se neste caso de um eu sou que não se caracteriza de modo algum pela visão e pela atitude teórica de posse, mas pela ação, pelo testemunho e pela relação de responsabilidade. Esta nova lógica da atestação e da responsabilidade, que substitui a da subjetividade transcendental, pressupõe a capacidade que a vida tem de se fazer pessoa, ao designar-se a si mesma e deixar-se atribuir a si uma ação, reconhecendo-se como o seu verdadeiro autor ${ }^{33}$.

Quatro são os grandes traços, que permitem, segundo Ricoeur, identificar esta vida que se significa e atesta como pessoa e que permitem ainda percebê-la no seu esforço temporal para ser: "a linguagem, a ação, a narrativa e a vida ética. Sou de facto, vida dotada da capacidade de poder falar, de poder agir, de poder contar a minha história, de poder considerar-me responsável pelos meus atos e deixar que estes me sejam imputados como ao seu verdadeiro autor». Estas capacidades, que outras formas de vida não possuem, atestam-se sempre na linguagem simbólica e narrativa e expõem a nova consciência, descentrada pela linguagem, à interpretação e ao conflito de interpretações suscitado pelo poder mimético dos símbolos ${ }^{34}$. A consciência não é já um dado imediato e adquirido para sempre, mas apenas «um primeiro passo que não pode ser seguido por nenhum outro, enquanto o l'ego de l'ego Cogito não se tiver recuperado no espelho dos seus objetos, das suas obras e finalmente dos seus atos»35. O que significa que a filosofia deve refletir

32 Cf. Maria Luísa Portocarrero (ed) Mal, símbolo e justiça, Coimbra, Faculdade de Letras, 2001.

33 P. Ricoeur, La symbolique du mal, pp. 14-15.

${ }^{34}$ Cf. Maria Luísa Portocarrero, A hermenêutica do conflito em P. Ricoeur, Coimbra, Minerva, 1992.

35 P. Ricoeur, Le conflit des interprétations, p. 21 
seriamente sobre a inscrição, vital, histórica e simbólica da razão e sobre a crise da sua ideia de fundamentação última. Mas, antes de mais, sobre as possibilidades poéticas e práticas que a liberdade humana tem de se atestar, em ordem a que se possa compreender a imbricação do eu e do outro na nova ideia de subjetividade singular.

$\mathrm{O}$ que faz a identidade de uma pessoa não são nesta perspetiva apenas os traços já herdados: isto é, os elementos biológicos que perduram ao longo do tempo; mas antes a coesão narrativa de uma vida, em que a diversidade das ações vividas - vida profissional, lúdica, familiar etc. - é reunida e unificada numa história com sentido. Ora, dizer que a pessoa tem uma história ou é a sua própria história, é reconhecer simultaneamente que não existe história de uma pessoa singular que não seja também a história de outras pessoas. A pessoa pode então entender-se a partir do conceito de racionalidade narrativa: é a vida examinada e narrada que diz, por meio de uma estrutura simultaneamente objetiva e reflexiva, a capacidade relacional e interativa ${ }^{36}$ daquele ente que se faz pessoa ${ }^{37}$. É ela que revela a historicidade do sujeito e que permite entender a intencionalidade de uma vida que se faz um si mesmo, apto e responsável, porque verdadeiramente capaz da linguagem e imputável. É, enfim, a distinção entre mesmidade e ipseidade que ilustra em Ricoeur a possibilidade de compreensão, sempre indireta, do que constitui uma subjetividade responsável. ${ }^{38}$ Esta não é nem o sujeito exaltado e virtual da modernidade, nem o sujeito humilhado de Nietzsche, mas o único ente capaz de falar e de se assumir como sujeito dos seus discursos; capaz de ser autor dos seus feitos, de ações inten-

36 Idem, "Lectio magistralis. Université de Barcelone, 24 avril 2001" in Domenico Jervolino, Une herméneutique de la condition humaine, Paris, Ellipses, 2002, p. 83 : "(...) le discours est adressé (...). Une même structure dialogale se laisse discerner au plan de 1'action : l'action est action avec, action contre, dans un contexte d'interaction, dramatisé par le conflit et la violence"

${ }^{37}$ Idem, ibidem : " (...) le récit dit le 'qui ' de l'action".

38 Cf. Idem, Soi-même comme un autre, Paris, Seuil, 1990. 
cionais e de iniciativas que mudam realmente o curso das coisas e que têm efeito sobre os outros; capaz de se situar numa narrativa de vida, capaz de ser, ao mesmo tempo, o narrador e o personagem da sua própria história e de, por meio da avaliação ética desta, poder constituir-se como ser imputável ${ }^{39}$. O ser humano é o único modo de vida cujo verdadeiro poder consiste na atestação de si mesmo, noção que o filósofo define "como uma espécie de crença, um crédito aberto à convicção prática, uma confiança na sua própria capacidade, que apenas recebe a sua confirmação do seu próprio exercício e da aprovação que lhe dão» ${ }^{40}$.

A ipseidade, verdadeiro rosto da nova subjetividade, requer como paradigmas as categorias éticas (e temporais) da atitude, do testemunho, da promessa ${ }^{41}$, do compromisso e da responsabilidade. E é justamente a função narrativa da linguagem humana o único suporte desta ipseidade ou autonomia intimamente ligada à pólis porque vinculada à solicitude para com o próximo e à justiça relativa a todos. ${ }^{42} \mathrm{O}$ que faz da pessoa um sujeito racional e autónomo é, pois, a sua capacidade de ser a origem do seu próprio agir (é vida que não está manietada pelas leis da causalidade física) e de por ele responder, isto é, a sua capacidade de auto-estima ${ }^{43}$ e imputação ${ }^{44}$. De outro modo, é a aptidão que ela possui para se submeter, como

39 Cf. Idem, Le juste, Paris, Esprit, 1995, pp. 30-32.

40 Idem, Le juste, 2 p. 89

${ }^{41}$ Cf. Idem, Le juste, 2, p. 92 : "En dépit du changement, nous attendons d autrui qu'il réponde de ses actes comme étant le même qui hier a agi et aujourd hui doit rendre des comptes et demain porter les conséquences. Mais s`agit-t- il encore de la même identité ? Ne faut-il pas, prenant pour modèle la promesse base de tous les contrats de tous les pactes, de toutes les ententes, parler d'un maintien de soi malgré le changement -maintien au sens de parole tenue ? C'est ici que je suggère, après d'autres, y compris Heidegger, de parler d'ipséité plutôt que de mêmeté».

42 Idem, Soi-même comme un autre, p. 30.

43 Idem, Le juste 2, p. 95 : "Nous appellerons estime de soi la forme éthique que revêt la revendication de singularité "

${ }^{44}$ Idem, ibidem, p. 97 : " L’imputabilité est la capacité d’être tenu pour responsable de ses actes comme étant leur véritable auteur». 
ser singular, às exigências de uma ordem simbólica e comunitária, que lhe permite inaugurar no mundo uma nova ordem e o exercício da responsabilidade. Tudo isto é possível pela capacidade de cada um para conduzir a sua vida de acordo com a ideia de coerência narrativa ${ }^{45}$. E com efeito, por meio da estreita correlação estabelecida pela narrativa entre ação, personagens e ideal de uma vida boa e ainda pelo tratamento narrativo dos personagens, através das peripécias que as conduzem à felicidade ou infelicidade, que a pessoa encontra, a verdadeira configuração da sua subjetividade ética ou ipseidade. Abordada como personagem da sua própria história, cada pessoa é capaz de referir a si os seus atos, percebendo que não é, de modo nenhum, nem uma entidade distinta das suas experiências, nem tão pouco um ser separado do outro. Pelo contrário é nos seus atos e por meio da relação com a alteridade que a pessoa se realiza enfim como vida significante. Daí a necessidade da inscrição desta forma de vida, que se faz sujeito capaz, não apenas nas exigências de uma ordem linguageira, simbólica ou narrativa, mas num corpo político que permita que as suas capacidades se tornem reais. Com efeito, as relações do sujeito com a alteridade são de dois tipos: com a alteridade interpessoal e com a institucional. A filosofia dialógica não pode limitar-se às relações com o tu, como o fez Gadamer, pois a este face a face falta sempre a relação ao terceiro que é tão primitiva como a relação ao tu. As linguagens institucionais da pólis estão, segundo Ricoeur, em continuidade com a forma de poder que caracteriza o homem capaz, conferem-lhe duração e estabilidade e projetam ainda "o horizonte da paz pública, compreendida como a tranquilidade da ordem ${ }^{46}$. Sem a mediação da alteridade que lhe outorga o poder institucional, o indivíduo é apenas um esboço de

45 Idem, ibidem, p. 94 : "Disons donc dès maintenant qu'est autonome un sujet capable de conduire sa vie en accord avec l'idée de cohérence narrative "; cf. ainda p. 98.

46 Idem, ibidem, p. 38. 
homem, o que significa que só é subjetividade verdadeira enquanto é um sujeito de direito ${ }^{47}$. Só a relação ao terceiro, enquanto pano de fundo da relação ao tu, é capaz de dar uma base segura à mediação institucional que é exigida pela categoria do cidadão. É a este nível que surge a linguagem dos contratos e dos pactos de todas as espécies que dão uma forma jurídica à trocas das palavras. Os pactos devem ser respeitados, tal é a regra do reconhecimento que ultrapassa sempre o face a face da relação eu-tu.

47 Idem, ibidem, pp. 39- 40. 